\title{
The use of dental anxiety questionnaires: a survey of a group of UK dental practitioners
}

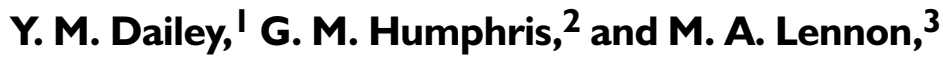

\begin{abstract}
Aim To determine the frequency of use of dental anxiety assessment questionnaires and factors associated with their use in a group of UK dental practitioners.

Method A postal questionnaire to all 328 dentists whose names appear in the British Society for Behavioural Sciences in Dentistry Directory. Information collected for each practitioner included gender, year of qualification, type of practice in which anxious dental patients were treated, treatment used to manage anxious dental patients, type and frequency of use of dental anxiety assessment indices.

Results Questionnaires were returned from 275 (84\%) practitioners. 269 were analyzed. Only 54 practitioners (20\%) used adult dental anxiety assessment questionnaires and only 46 $(17 \%)$ used child dental anxiety assessment questionnaires. Male practitioners were more likely to report questionnaire use in comparison with females $(P<0.05)$, when treating dentally anxious adults $(26 \% \mathrm{v} 14 \%)$. In addition, practitioners providing intravenous sedation were more likely to use an adult dental anxiety questionnaire $(P<0.04)$ than those who did not use intravenous sedation ( $29 \% \mathrm{v} 15 \%)$. The type of treatment provided had a significant association with the use of child dental anxiety. Those providing general anaesthesia $(P=0.03)$ and hypnosis $(P=0.01)$ for dentally anxious children were more inclined to use a questionnaire.

Conclusion The use of pre-treatment dental anxiety assessment questionnaires was low in this group of dentists. Male practitioners and those providing intravenous sedation, general anaesthesia or hypnosis seem more likely to use dental anxiety assessment questionnaires.
\end{abstract}

Tn the United Kingdom there are no specialist lists of dentists providing treatment for anxious patients. The British Society for Behavioural Sciences in Dentistry Directory (BSBSD) publishes however, the details of 328 practitioners who have a special interest in treating patients with dental anxiety. The directory is produced by the BSBSD, which aims to promote the application of the social and behavioural sciences in the practice of dentistry. ${ }^{1}$

The intensity and nature of dental anxiety varies from one individual to another. It has been suggested that the adoption of formal

${ }^{1}$ Lecturer in Primary Dental Care, Department of Clinical Dental Sciences, University of Liverpool; ${ }^{2}$ Senior Lecturer in Clinical Psychology, Department of Clinical Psychology, University of Liverpool; ${ }^{3}$ Professor of Dental Public Health, Department of Clinical Dental Sciences University of Liverpool

Correspondence to: Y. M. Dailey, Room 313 The Edwards Building, University of Liverpool, Daulby Street, Liverpool L69 3GN

email:Y.M.Dailey@liverpool.ac.uk

REFEREED PAPER

Received 18.07.00; Accepted 23.11.00

(c) British Dental Journal 2001; 190: 450-453 psychometric measures would be of benefit for accurate assessment of a patient's dental anxiety from initial contact. ${ }^{2}$

There are a variety of self-reported dental anxiety assessments available. Probably the most well known adult questionnaire designed to assess dental anxiety is Corah's Dental Anxiety Scale (DAS). ${ }^{3}$ The DAS consists of four questions about different dental situations. Each question is scored from 1 (not anxious) to 5 (extremely anxious) so the range of possible scores is 4 to 20 . Scores of 15 or more indicate profound anxiety. ${ }^{4}$ The scale has been modified and some important additional features added to aid assessment. These include, a simplified and consistent answering scheme, a further question on local anaesthesia and psychometrically defined cut off levels. ${ }^{5,6}$ Many scales are also available to measure children's fear. In a recent review of the literature, Aartman et al. recommended the Children's Fear Survey Schedule Dental Subscale (CFSS-DS). ${ }^{7}$ It consists of 15 questions, each scored from 1 (not afraid) to 5 (very afraid). A score of 45 or higher represents high levels of anxiety.

The attempts to assess dental anxiety have been driven, in the main, by research purposes. Numerous studies have been published collecting the self reports of dental anxiety, as the primary outcome variable. For example, indicators of pre and post treatment anxiety levels have been collected to test various anxiety management techniques. ${ }^{8}$ Many of these studies have been reported from specialized dental anxiety clinics within America, ${ }^{9}$ Sweden ${ }^{10}$ and The Netherlands. ${ }^{11}$ Research concerning dental anxiety assessment by UK dental practitioners is sparse. However, interest in clinical audit and initiatives to support research activity in primary care indicate that systematic assessment of dental anxiety by dental practitioners may be more common than research reports suggest. Within clinical dentistry assessment questionnaires and indices are routinely used, for example in orthodontics, ${ }^{12,13}$ and periodontics, ${ }^{14,15}$ as part of patient assessment, diagnosis, treatment planning and evaluation of treatment outcomes. ${ }^{16}$ In addition, the specialized dental anxiety clinics in the Netherlands employ the routine use of dental anxiety assessment questionnaires, for referral of dentally anxious patients into their treatment programs. ${ }^{17}$ Their current recommendations advise that referred patients have scores at or above the cut off points of at least two standardized dental anxiety questionnaires.

The practitioners in the BSBSD have a special interest in treating anxious patients. It was predicted, in the absence of published evidence, that these practitioners were likely to use dental anxiety assessment questionnaires. Therefore, the first aim of the study was to determine the frequency of use of dental anxiety assessment questionnaires for child and adult patients. In addition, some evidence suggests that practitioners' choice of behavioural management techniques varies by their gender, age and qualifications. ${ }^{18}$ Hence, the second aim was to identify the dental practitioner characteristics and clinical approaches that were associated with the use of dental anxiety questionnaires. 


\section{Method}

\section{Subjects}

All 328 dentists in the BSBSD were sent a 3-page questionnaire. The questionnaires were distributed by post in June 1999, with a stamped addressed reply envelope and covering letter. The questionnaires were anonymous, although practitioners were asked to provide their details if they wished information from the study to be sent to them. The return date for the questionnaires was specified as 4 weeks after postage.

\section{Questionnaire}

The questionnaire consisted of six question areas including:

1 Gender of practitioner

2 Year of qualification

3 The type of practice (private, national health general practice, community, hospital and other) in which their dentally anxious adult and child patients were treated

4 The anxiety management techniques employed (behavioural management, relative analgesia, intravenous sedation, oral sedation, general anaesthesia, hypnosis and other)

5 Percentage of dentally anxious adult or child patients treated each week and

6 The frequency of use of six specified dental anxiety assessment indices, for child and adult patients.

The percentage of working week used for treating adult and child dentally anxious patients was recorded by a five point Likert type scale with labels specified for $100 \%, 75 \%, 50 \%, 25 \%,<25 \%$. Frequency of use of dental anxiety assessment was recorded using a five point Likert type scale with labels specified for each category namely: not at all, rarely, sometimes, often and always. The practitioner was asked to record in free text details of any other assessment methods they may use, which were not listed in the questionnaire.

Initially the questionnaire was piloted using six general dental practitioners (GDPs) and two community dental practitioners (CDPs). Minor alterations were made. For example, specification of the age range required for children ( $0-16$ years).

\section{Statistical analysis}

The questionnaires received were analyzed using the statistical package SPSS V9.0 for Windows ${ }^{\mathrm{TM}}{ }^{19}$ Summary statistics were calculated to include frequencies and where appropriate means and standard deviations. Logistic regression was employed to identify factors that were associated with the use of a dental anxiety assessment questionnaire. This analysis searches for the best combination of independent variables, which is associated with the dependent variable (use of an anxiety assessment questionnaire). $P$ values equal to or less than 0.05 were considered statistically significant.

\section{Results}

A total of $84 \%$ (275/328) practitioners responded. Six did not fully complete their questionnaires; data were analyzed for $269(82 \%)$ respondents. Forty-six per cent of respondents were female $(123 / 269)$. The majority of respondents qualified in the 1970s and 1980s $(n=217 ; 81 \%)$ (Table 1$)$.

To establish the consistency of the information collected, a third $(n=109)$ of the original sample $(n=328)$ were sent a repeat questionnaire. No formal test-retest could be performed, as the questionnaire was anonymous to increase the response rate. Of the 109 distributed, 64 (59\%) were returned. There was no significant difference in the proportion using anxiety assessment questionnaires $\left(\chi^{2}=0.73, \mathrm{df}=1, P>0.05\right)$ when compared with the main sample.
Table I Respondents year of qualification

\begin{tabular}{lc}
\hline Year of qualification & $\begin{array}{c}\text { Number of respondents } \\
(n=269)\end{array}$ \\
\hline & \\
Pre-1960 & 3 \\
$1960-1969$ & 23 \\
$1970-1979$ & 92 \\
$1980-1989$ & 125 \\
$1990-1999$ & 26 \\
\hline
\end{tabular}

\section{Practice setting}

The community dental service was the predominant setting for treating anxious adults ( 88 respondents) and anxious children (103 respondents) (Table 2). The general dental service was also an important setting for children (91 respondents), and alone (46 respondents) or in combination with private practice (48 respondents) for adults. Five respondents $(2 \%)$ did not provide any treatment for anxious adults and $20(7 \%)$ did not provide treatment for anxious children.

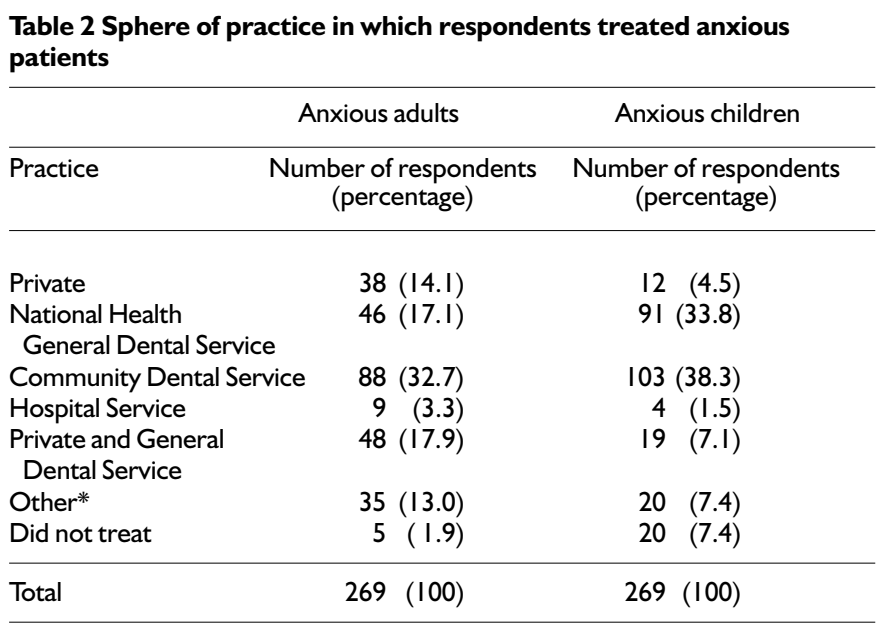

*Patients treated in primary and secondary care

Thirty two per cent of respondents (85/264) treating anxious adults estimated that the proportion of anxious adults treated within their working week was $25 \%$ or more. Forty per cent $(100 / 249)$ estimated the proportion of anxious children treated within the working week was $25 \%$ or more.

\section{Management techniques}

The management techniques employed by the respondents when treating anxious adults or children are presented in Table 3. Behavioural management techniques were used most frequently (adult: 93\%, 245/269, child: 96\%,240/269). The use of relative analgesia, general anaesthesia and hypnosis was similar for both anxious adults and children. Intravenous sedation was used mainly for adults. Included in the 'other' category for anxious adults $(5 \%$, $14 / 269$ ) were those respondents who used oral sedation and the minority who indicated use of other techniques such as homeopathy aromotherapy and neurolinguistic programming).

\section{Dental anxiety questionnaires}

The use of dental anxiety assessment questionnaires was low. Twenty per cent of respondents (54/264) used adult dental anxiety assessment questionnaires and 17\% (46/249) used child dental anxiety assessment questionnaires. Table 4 shows the variety of dental anxiety assessment questionnaires used by the practitioners. Many of the practitioners indicated that they used more than one dental anxiety assessment questionnaire. For adults the Modified Dental Anxiety 
Table 3 Respondents reported use of anxiety management techniques

\begin{tabular}{lcc}
$\begin{array}{l}\text { Anxiety management } \\
\text { technique }\end{array}$ & $\begin{array}{c}\text { Anxious adults* } \\
(n=264)\end{array}$ & $\begin{array}{c}\text { Anxious children* } \\
(n=249)\end{array}$ \\
\hline At least one technique & $264(100 \%)$ & $249(100 \%)$ \\
Behavioural management & $246(93.2 \%)$ & $240(96.4 \%)$ \\
Relative analgesia & $134(51.1 \%)$ & $145(58.2 \%)$ \\
General anaesthesia & $79(29.9 \%)$ & $107(40.5 \%)$ \\
Intravenous sedation & $107(43.0 \%)$ & $18(7.2 \%)$ \\
Hypnosis & $79(29.9 \%)$ & $61(24.5 \%)$ \\
Other & $14(5.3 \%)$ & $3(1.2 \%)$ \\
\hline
\end{tabular}

${ }^{*}$ Respondents were able to indicate use of more than one technique tOral sedation, hypnotherapy, aromatherapy, neurolingusitic programming

Table 4 Respondents self-report use of anxiety assessment indices

\begin{tabular}{|c|c|c|c|}
\hline $\begin{array}{l}\text { Numbe } \\
\text { respond } \\
(n=2\end{array}$ & $\begin{array}{l}\text { of of } \\
\text { ents } \\
64)\end{array}$ & $\begin{array}{l}\text { Numbe } \\
\text { respond } \\
(n=2\end{array}$ & $\begin{array}{l}\text { er of } \\
\text { lents } \\
249)\end{array}$ \\
\hline $\begin{array}{l}\text { Use of at least } \\
\text { one index listed below }\end{array}$ & 54 & $\begin{array}{l}\text { Use of at least } \\
\text { one index listed below }\end{array}$ & 12 \\
\hline Corah's Dental Anxiety Scale & 26 & Visual Analogue Scale & 19 \\
\hline $\begin{array}{l}\text { Modified Dental Anxiety } \\
\text { Scale }\end{array}$ & 32 & Venham Picture Scale & \\
\hline Getz Dental Belief Index & 5 & Frankl Scale & \\
\hline Dental Fear Survey & 20 & Children's Dental Fear Picture Test & \\
\hline $\begin{array}{l}\text { Spielberger State Trait } \\
\text { Anxiety Inventory }\end{array}$ & 9 & Corah's Dental Anxiety Scale ${ }^{\dagger}$ & 18 \\
\hline Other & 3 & Other & \\
\hline
\end{tabular}

*Respondents were able to indicate the use of more than one index

tSame as adult scale

Scale was the most frequently used questionnaire and for children the Visual Analogue Scale. The category 'other' included three respondents who used self devised dental anxiety assessment questionnaires, for their adult patients. For child patients seven respondents used 'other' assessment methods not included on the study questionnaire. Five were self-devised, two used the Modified Child Dental Anxiety Scale. ${ }^{20-21}$ Sixty-nine per cent of those respondents (37/54) using adult indices did so sometimes, or rarely. The frequency of use by the remaining $31 \%(17 / 54)$ of those respondents was often, or always. The frequency of use of child dental anxiety assessment indices was similar.

Tables 5 and 6 show the results of the logistic regression analysis undertaken to establish those factors, which were associated with the use of the dental anxiety assessment questionnaires in adults and children. Independent factors included in the model were practitioner's characteristics including gender and date of qualification, practice setting and clinical approaches to anxiety management. To facilitate the analyses for adults the practice setting variable was condensed by combining the categories: hospital $(n=9)$ and other $(n=35)$. For the child analyses private $(n=12)$ was combined with private and national health general dental service $(n=19)$. In addition the small number of practitioners providing 'other' treatment for adults and children ( $n=14$ and $n=3$ respectively) were not included in the analysis.

For adult patients the gender of the practitioner had a significant association with the use of a questionnaire $(\mathrm{B}=0.76, \mathrm{SE}=0.38$, $P<0.05)$, the male practitioners being more likely to use an anxiety assessment questionnaire than females (26\% v 14\%). Significant association was also found with those practitioners providing intravenous sedation. They were more inclined to use a dental anxiety assessment questionnaire $(\mathrm{B}=0.76, \mathrm{SE}=0.35, P<0.05)$ than those who did not use intravenous sedation $(29 \% \mathrm{v} 15 \%)$. The practice setting was not associated with the use of dental anxiety questionnaires.

Table 6 shows a significant association between the use of dental anxiety assessment questionnaires and general anaesthesia $(\mathrm{B}=0.89, \quad \mathrm{SE}=0.41, \quad P=0.01)(22 \% \mathrm{v} 15 \%)$ and hypnosis $(\mathrm{B}=0.99, \mathrm{SE}=0.39, P=0.01)(26 \% \mathrm{v} 16 \%)$, during the management of the anxious child. The practice setting variable was not associated with the use of dental anxiety questionnaires.

\section{Discussion}

The response rate of over $80 \%$ achieved in this study was favourable in comparison with other postal questionnaires in primary care settings. Nevertheless this study population remains a self selected group of practitioners and the results from our sample cannot be extrapolated to the wider population of general dental practitioners not included in the BSBSD directory.

The results indicated that dental practitioners with a special interest in dental anxiety were unlikely to use any formal method of dental anxiety assessment. It was surprising that the expected high use of anxiety assessment questionnaires was not supported by the results of the study. The use of these questionnaires for both adult and child patients was low, with only $20 \%$ (55/269) of respondents using them. In planning the study we had anticipated a high frequency of use of anxiety questionnaires and therefore questions exploring the reasons for this low use were not included. However, some explanations can be put forward that require further consideration and research.

Firstly, we have anecdotal reports that some practitioners believe that the routine use of anxiety assessment questionnaires may harm the dentist patient relationship by focusing on specific anxiety provoking events. There is scientific evidence that these concerns are not justified, Kent ${ }^{22}$ found that pre treatment assessment of anxiety and pain had no influence on adult patients' subsequent anxiety and discomfort. Furthermore, there may be benefits from the assessment of dental anxiety, at least for child patients. Carlsen

Table 5 Logistic regression analysis: factors associated with the use of an adult anxiety assessment questionnaires

\begin{tabular}{llllll}
\hline Dependent Factor & Independent factors & Beta & SE & df & $P$ \\
\hline \multirow{2}{*}{ Use of a questionnaire $^{*}$} & Gender $^{\dagger}$ & & & \\
& Intravenous sedation $^{\ddagger}$ & 0.756 & 0.376 & I & 0.04 \\
\end{tabular}

$\mathrm{n}=264,{ }^{*}$ no $=0$, yes $=\mathrm{I},{ }^{\dagger}$ female $=0$, male $=\mathrm{I}$, ${ }^{\ddagger}$ else $=0$, intravenous sedation $=\mathrm{I}$

Table 6 Logistic regression analysis: factors associated with the use of a children's anxiety assessment questionnaire

\begin{tabular}{llllll}
\hline Dependent factor & Independent factors & Beta & SE & df & $P$ \\
\hline \multirow{2}{*}{ Use of a questionnaire $^{*}$} & General anaesthesia $^{\dagger}$ & 0.892 & 0.414 & & 0.03 \\
& Hypnosis $^{\ddagger}$ & 0.989 & 0.389 & I & 0.01 \\
\hline
\end{tabular}

$n=249,{ }^{*}$ no $=0$, yes $=1,{ }^{\dagger}$ else $=0$, general anaesthetic $=I,{ }^{\ddagger}$ else $=0$, hypnosis $=1$ 
et al. ${ }^{23}$ found that while pre-treatment enquiries of children concerning both anxiety and pain had no effect on disruptiveness or pain experience, assessment did however, appear to reduce anxiety about dentistry.

Secondly, many dentists believe that they can reliably recognize dental anxiety in their patients based on clinical impression alone. However research indicates that this is not always the case. There has been far from perfect agreement between patients' self-reports and clinician ratings of patients' dental anxiety in validation studies. ${ }^{3,5}$ Moreover, patients have admitted, on detailed enquiry, to attempt to mask their dental anxiety so as to prevent disruption to the dentists' treatment schedule. ${ }^{1,24}$

Thirdly, and in our view the most likely explanation is that the majority of respondents had not been aware of the availability of dental anxiety questionnaires. The distribution of the practitioner's year of qualification was similar to that on the dental register ${ }^{25}$ with most practitioners graduating in the 1970s and 1980s. Few would have received specific behavioural science teaching, which became a requirement in the undergraduate course in $1990 .{ }^{26}$ Furthermore, the opportunity to practice (as opposed to gaining awareness of) anxiety assessment and management techniques within the dental schools is limited. ${ }^{27}$ It is interesting that, in our sample, dentists who provided intravenous sedation for anxious adults, and general anaesthesia or hypnosis for anxious children were more likely to be using anxiety assessment techniques. These are all specialist procedures; it is possible that dentists came across the relevant assessment techniques during their postgraduate education.

It was also noticeable that the most frequently used dental anxiety questionnaire was the MDAS. ${ }^{5}$ The original dental anxiety scale introduced by Corah in $1969^{3}$ has been widely used in dental research. However the modified version introduced by Humphris et al., in $1995^{5}$ was probably very accessible to those in our sample working within the UK community dental service. Further more, why were the male practitioners more inclined to use the questionnaires? We know from medical research that the gender of practitioner has an effect upon the use of patient management techniques, ${ }^{28-30}$ with male practitioners being less inclined to engage the patient in discussions about their feelings. ${ }^{31}$ It is possible therefore, that the male practitioners in this study, were using the dental anxiety questionnaires, as a method of communication.

What then is the way forward? The evidence regarding the benefit of implementing dental anxiety assessment questionnaires within UK general dental practice is sparse. We know that administering a dental anxiety assessment questionnaire can be brief, especially if it is completed in the dental waiting room. It allows patients to indicate their anxiety and practitioners to plan treatment accordingly. ${ }^{32-36}$ The authors are therefore, currently undertaking a randomized control trial within UK general dental practice. The aim is to try to establish the benefit to both patients and practitioners of the routine use of dental anxiety assessment questionnaires.

\section{Conclusion}

The use of pre-treatment anxiety assessment questionnaires was low in this self-selected specialist group of dentists. Male practitioners and those providing intravenous sedation, general anaesthesia or hypnosis seem more likely to use anxiety assessment questionnaires.

1 The British Society for Behavioral Scinces in Dentisty Directory. A Guide to care for anxios and phobic dental patients. 2000: London

2 Frazer M, Hampson S. Some personality factors related to dental anxiety and fear of pain. Br Dent J 1988; 165: 436-439.

3 Corah N L. Development of a dental anxiety scale. J Den Res 1969; 48: 596.

4 Corah N L, Gale E N, Illig S J. Assessment of a dental anxiety scale. J Am Dent Assoc 1978 ; 97: 816-819.

5 Humphris G M, Morrison, T Lindsay S J E. The modified dental anxiety scale-validation and United Kingdom norms. Comm Dent Health 1995; 12 143-150.

6 Humphris G M, Freeman R, Campbell J, Tuutti H, D’Souza V. Further evidence for the reliability and validity of the Modified Dental Anxiety Scale. Int Dent J 2000; 50:367-370.

7 Aartman I, Everdingen T, Hoogstraten J, Schuurs. A. Self-report measurements of dental anxiety and fear in children: A critical assessment. J Dent Child 1998; 65: 252-258.

8 Jackson C, Lindsay S. Reducing anxiety in new dental patients by means of leaflets. Br Dent J 1995; 179: 163-167.

9 Milgrom P, Weinstein P. Dental fears in general practice: new guidelines for assessment and treatment. Int Dent J 1993 Jun; 43: 288-293.

10 Johansson P, Berggren U. Assessment of dental fear. Acta Odont Scand 1992; 50: 43-49.

11 Johansson P, Berggren U, Hakeberg M, Hirsch J-M. Measures of dental beliefs and attitudes : their relationships with measures of fear. Comm Dent Health 1993; 10: 31-39.

12 Lindauer S J, Thresher A A, Baird B W, Sheats R D, Rebellato J. Orthodontic treatment priority: a comparison of two indices. JClin Pediatr Dent 1988; 22: $125-131$

13 McGuinness N J, Stephens C D. An introduction to indices of malocclusion. Dent Update 1994; 21: 140-144.

14 Galgut P. A comparison of different indices used in the clinical assessment of plaque and gingival bleeding. Clin Oral Investig 1999; 99: 96-9.

15 Benamghar L, Penaud J, Kaminsky P, Abt F, Martin J. Comparison of gingival index and sulcus bleeding index as indicators of periodontal status. Bull World Health Organ 1982; 60:147-51.

16 Matthews D C. Decision making in periodontics: a review of outcome measures. J Dent Educ 1994 ; 58: 641-647.

18 Aartman I H A, Eijkman M A J, Makkes P C. Behandeling van angstige patienten in instellingen voor bijzondere tandheelkunde. Van lokale initiatieven tot overkoepelend orgaan. Nederlands Tijdschrift voor Tandheelkunde 1998; 105: 365-367

17 Wright F A, Giebartowski J E, McMurray N E. A national survey of dentists management of children with anxiety or behaviour problems. Aust Dent J 1991; 36: 378-383.

19 SPSS for Windows Base Version 9.0.0 Chicago: SPSS Inc, 1998.

20 Wong G, Humphris G M, Lee G T R. Preliminary validation and reliability of the Modified Child Dental Anxiety Scale. Psychol Reports 1998; 83: 1179-1186.

21 Christophorou S, Lee G T R, Humphris G M. The reliability and validity of the Modified Child Dental Anxiety Scale: a study of Greek Cypriot school children. Europ J Paediat Dent 2000; 2: 75-81.

22 Kent G. Effects of pre-treatment inquiries on dental patients postappointment ratings of pain. Br J Med Psychol 1986; 59: 97-99.

23 Carlsen A, Humphris G M, Lee G T R, Birch R H. The effect of pretreatment enquiries on child patients post-treatment ratings of pain and anxiety. Psychol and Health 1993; 8: 165-174.

24 Lahti S, Tuuti H, Hausen H, Kaariainen R. Comparison of ideal and actual behaviour of patients and dentist during dental treatment. Community Dent Oral Epidemiol 1995; 23: 374-378.

25 General Dental Council Register 1999.

26 General Dental Council. Guidance on the teaching of behavioural sciences, 1990.

27 Pine C M, McGoldrick P M. Application of behavioural sciences teaching by UK dental undergraduates. J Dent Educ 2000; 4: 49-5623.

28 Bernzweig J, Takayama J I, Phibbs C, Lewis C, Pantell R H. Gender differences in physician-patient communication. Evidence from pediatric visits. Arch Pediatr Adolesc Med 1997; 151: 586-591.

29 Roter D, Lipkin M Jr, Korsgaard A. Sex differences in patients' and physicians' communication during primary care medical visits. Med Care 1991; 29: 1083-1093.

30 Douglas H, Reisine S T, Cipes M H. Characteristics and satisfaction of the patients of male versus female dentists. J Am Dent Assoc 1985; 110: 926-929.

31 Roter D L, Hall J A. Why physician gender matters in shaping the physician-patient relationship. J Womens Health 1998; 7: 1093-1097.

32 Kvale G, Berg G, Raadal M. The ability of Corah's Dental Anxiety Scale and Spielberger's State Anxiety Inventory to distinguish between fearful and regular Norwegian dental patients. Acta Odontol Scan 1998: 56: 105-109.

33 Milgrom $P$, Weinstein P. Dental fears in general practice: new guidelines for assessment and treatment. Int Dent J 1993; 43: 288-293.

34 Aartman I H A, Reliability and validity of the short version of the dental anxiety inventory. Comm Dent Oral Epid 1998; 26: 350-354.

35 Berggren U, Carlsson S G, Hakeberg M, HagglinC, Samsonowitz V. Assessment of patients with phobic dental anxiety. Acta Odontol Scand 1997; 55: 217-222.

36 Stouthard M E, Hoogstraten J. Prevalence of dental anxiety in the Netherlands. Comm Dent Oral Epid 1990; 18: 139-142. 